\title{
GENETICS AND ORAL DISEASES: A SCOPING REVIEW
}

\author{
Heba M Fayed", Hala H Yassin ${ }^{* *}$, Soha A Hassan ${ }^{* * *}$ and Waheed A Mohamed
}

\begin{abstract}
Introduction: Recently genes act as hereditary blueprints of humans in our modern evidencebased dentistry era, Genomic wide association studies (GWAS) have investigated genetic and environmental factors which are considered instruments in genesis of complex and wide range of oral \& maxillofacial disorders and syndromes. Their findings indicated that genetic mutation \& polymorphisms are involved in periodontal diseases and temporomandibular disorders (TMDs) etiology \& play a role by contributing to small effects and in determining the course and outcome of these disorders. Oral tissues are unique in different aspects, but they share many genetic etiopathogenesis of various disorders that are common to tissues throughout the body. Conditions affecting oral and maxillofacial tissues may occur as a part of systemic conditions or syndromes or single gene mutation or multifactorial gene disorders or X-linked diseases.
\end{abstract}

Objectives: This article provides scopic reviews on the previous and current human genetics factors association with oral, periodontal, and temporomandibular disorders, which may lead to revolutionized treatment and prevention plans in the future.

Methods: Databases search of literature were reviewed including Egyptian knowledge bank (EKB), and PubMed (NIH) by using scientific terms for periodontal disorders, oral diseases, TMDs and genetic mutation. Bibliographies of additional articles were reviewed to identify additional studies of relevance.

KEYWORDS: Single gene disorders, X-linked, Gene mutations, Periodontal diseases, Temporomandibular disorders, Genetic multifactorial.

\section{INTRODUCTION}

Human genetic disorder can be defined as any disease that are caused by alteration in one or more gene. This includes the study of both cellular changes controlled by DNA and the inherited characters. Oral diseases with genetic etiology expand to represent more than one category of genetic disorders. Many periodontal diseases are multifactorial that show the

\footnotetext{
* Lecturer, Oral Surgery Department, Faculty of Dentistry, October 6 University.

** Professor of Oral Medicine \& Periodontology Department, Faculty of Dentistry, October 6 University.

*** Associate Professor of Cell Biology, Basic Science Department, Faculty of Dentistry, October 6 University
} 
involvement of environmental factors side by side to one or more genetic factor. On the other hand, a lot of single gene and chromosomal disorders express oral manifestations. Chromosomal anomalies show a wide of phenotypical alteration that extend to include oral manifestations. Such anomalies either belongs to autosomes or sex chromosomes affecting oral health.

In the past, such structural factors, as dental occlusion was given a considerable attention, with the assumption that malocclusion could change proper muscular and TMJ function, and therefore, lead to temporomandibular disorders (TMDs) ${ }^{(1-4)}$. TMDs is a scientific term represents a group of complicated musculoskeletal conditions involving the joint, muscles and associated structures and is characterized by orofacial pain, physical impairment, and noise in the temporomandibular joint (TMJ) ${ }^{(5,6)}$. However, recent studies accepted the biopsychosocial model of the multifactorial nature of TMD, which depends on contribution of biological, psychological, and social factors to TMD development (7). This conceptual model emphasizes environmental factors influence and its association with genetic aspects and synergistic action of gene-environment interactions in modulating TMJ dynamics ${ }^{(8-10)}$.

Although some studies results showed interesting associations ${ }^{(1-10)}$, the exact genes and genetic polymorphisms involved in the TMD risk or protection remain unknown. This paper is an attempt to shed light on the relevant genetic diseases affecting oral region periodontal tissues and temporomandibular joint.

\section{Multifactorial disorders:}

The genetic contributions to etiology of periodontal diseases determines the genetic mutation or the resulted proteins that cause alteration in the phenotype. These genetic contributions usually act in concert with certain environmental factors (e.g., microbes, diet, or smoking). The external factors can provoke the genetic changes which has an initial readiness to cause disease. The genetic factors (i.e., disease alleles) contributing to complex diseases are prevalent in the population ${ }^{(11)}$. Periodontal diseases are a group of chronic multifactorial inflammatory disorders that affect the periodontium. Severe, irreversible forms of periodontitis are highly attributed to genetic factors in terms of etiology ${ }^{(12)}$.

Alzheimer's disease (AD) is a neurodegenerative disorder characterized by a progressive decline in memory, judgment, and cognitive skills. This condition may also be associated with higher levels of inflammatory markers and antibodies in individuals with periodontal disease ${ }^{(13)}$.

According to Kamer et al ${ }^{(13)}$ specific pathogens contribute to the "initiation, maintenance and progression" of plaque biofilm and periodontal disease. As the biofilm matures, the periodontal bacteria thrive while simultaneously defending and protecting the ecosystem against foreign antigen invasion via exogenously derived antibacterial and host defense mechanisms. Potentially, the periodontal infection can metastasize to other areas distant from the oral cavity, triggering an inflammatory response that damages extraoral tissue.

\section{Gene mutations effects on oral health:}

Genes coding, transcription, and mutations have been reported in literature to influence teeth genesis, positional anomalies, and morphology. Site specific patterns for anteroposterior position of teeth are influenced by HOX genes. ${ }^{(14)}$

Posterior site development of tooth buds can be influenced by agenesis of third molar and lower second premolar, which MSX1 regulator gene is responsible for. ${ }^{(15)}$

Palatal displacement of canines leading to impaction of ectopic tooth is related to tooth agenesis and agenesis of lower second premolar contributes to positional anomalies of canines. ${ }^{(16)}$ 
Among other famous causes of ectopic dentition is hyperdontia. Hyperdontia is a term used to describe supernumerary teeth, evidence of hyperdontia being closely related to genetics is explained in literature. Hyperdontia has been suggested to be autosomal dominant either in isolation or as a part of a syndrome, such as cleidocranial dysplasia and Gardner syndrome. ${ }^{(17)}$

Cleidocranial dyplasia is the most famous syndrome linked with supernumerary teeth. It is an autosomal dominant skeletal dysplasia caused by mutations in RUNX2 gene, responsible for encoding transcription factor activating osteoblast differentiation. ${ }^{(18)}$

Gardner syndrome is a rare autosomal dominant condition, caused by mutation in APC at $5 \mathrm{q} 21$, and characterized by dental anomalies such as impacted or unerupted teeth, hypodontia, abnormal tooth morphology, supernumerary teeth, compound odontomas, dentigerous cysts. ${ }^{(19)}$

In this regard, tooth agenesis, position anomalies, and morphology are a component of genetically controlled dental condition. (e.g., MSX1, MSX2, DLX5, PAX9). Such malposition, failure of eruption and impacted teeth are highly influenced by dentition aplasia. ${ }^{(20)}$

Genome wide association analysis (GWAS) revealed that top genes of association with severity of periodontitis and colonization of microorganisms include NIN, ABHD12B, WHAMM, AP3B2, CPEB1, HGD, ZNF675, EMK1, TNFRSF10B, HTR4, WDR59, JDP2, OTOF, ANGEL2, etc. ${ }^{(21)}$. GWAS is a recent development in the field of research. It highlights suggestive loci that could play an important role in periodontitis. However, the method is expensive and technique sensitive. Many GWAS in periodontitis has been carried out and has shown differential expression of varied genes ${ }^{(22-24)}$.

Regarding genomic association with temporomandibular joint disorders (TMDs); genes involved in serotonin activity and metabolism were investigated in different studies. Serotonin transporter gene regulates the activity of serotonin, which has two polymorphic regions: the variablenumber tandem-repeat (VNTR), and the gene-linked polymorphic region (LPR). Higher transcriptional activity was found to be more in the long alleles when compared to the short alleles. This causes an increased uptake of serotonin, leading to decreased extracellular concentration of serotonin ${ }^{(25)}$. Higher risk of TMD can be correlated to presence of long alleles while the presence of a short allele reduces such risk ${ }^{(26)}$.

\section{ANKH gene}

The murine ank gene and the human homolog ANKH gene have been associated with ankylosing spondylitis in humans. In the ANKH-OR polymorphic region of the ANKH gene, two alleles were identified: the 1-allele and the 2-allele. Higher risk of a particular TMD diagnosis is related to Genotypes, both $1 / 1$ and $2 / 2$ in particular manifestations such as disc displacement without reduction (closed lock) ${ }^{(27)}$

\section{HLA}

It is the human major histocompatibility complex which was identified with specific alleles that have been associated with TMJ spondyloarthropathies and can also affect the peripheral and axial joints. (28) Higher risk for TMJ degenerative processes progress might be associated with the subjects of these alleles due to the presence of infectious agents with ensuing host interactions and the resulting inflammatory response being determined by their HLA phenotype ${ }^{(28,29)}$.

\section{Extracellular matrix metabolism (MMP)}

Metalloproteinases (MMPs) production, an inflammatory cytokine is modulated by compressive stress on the synovial cells of the temporomandibular joint (TMJ). ${ }^{(30)}$ 
They play a central role in many biological processes, such as normal tissue remodeling, embryogenesis, angiogenesis, wound healing and in diseases such as atheroma, cancer, arthritis, tissue ulceration and TMJ degenerative disease. ${ }^{(31)}$ Currently, 23 MMP genes have been identified in humans, and most are multidomain proteins ${ }^{(32)}$. Their activity is regulated not only at the gene expression. Level, but is also regulated by inhibitors, including an MMP-specific family, tissue inhibitors of metalloproteinases (TIMPs) ${ }^{(33)}$.

\section{Catecholamine activity and metabolism}

Catechol-O-methyltransferase (COMT) is an enzyme that catalyzes the degradation and reuptake of catecholamines, including the neurotransmitters epinephrine, nor-epinephrine, and dopamine. There are two enzymes encoded by COMT gene that is located at chromosome $22 ; 1^{\text {st }}$ enzyme is soluble COMT (S-COMT) and the $2^{\text {nd }}$ is membrane-bound COMT (MB-COMT) with 221 and 271 amino acids, respectively. Many of the genetic polymorphisms in the COMT gene have been linked to emotional disorders, stress, ${ }^{(34)}$ painful conditions, ${ }^{(35,36)}$ and TMD ${ }^{(37-43)}$.

\section{Apoptosis (programmed cell death)}

It seems to be an important mechanism in prenatal and post-natal TMJ development. Bcl2 (B-cell leukemia/lymphoma 2) and Bax (Bcl2-associated X protein) are the genes that have been associated with apoptosis at the condylar cartilage. In addition, Bcl2 appears to have an important role in maintaining survival of chondrocytes during their proliferation, differentiation, and maturation. ${ }^{(44,45)}$

\section{Orofacial pain prospective evaluation risk and assessment (OPPERA) study}

The OPPERA (Orofacial Pain: Prospective Evaluation and Risk Assessment) is the first genetic association study of TMD that have investigated a substantial number of pain related candidate genes. It is a wide 7-year prospective cohort study intended to assess environmental, biopsychosocial factors and determine genetic elements precipitating in TMDs. A group of scientists started the study and evaluated the results. Regarding the role of genetic factors, seven genes were found to be related to TMD, they provide tentative evidence that chronic TMD is influenced by genetic contributions within several gene loci, including NR3C1, CAMK4, CHRM2, IFRD1, GRK5, HTR2A and COMT.

\section{NR3C1}

Three polymorphisms of the glucocorticoid receptor NR3C1 gene were associated with a lower risk of TMD. The receptor is the binding site of cortisol and a major element of the hypothalamicpituitary-adrenal system, which has been correlated with the pathophysiology of TMD.

\section{CAMK4, CHRM2, IFRD1, GRK5}

Also, the polymorphisms of the calcium/calmodulin-dependent protein kinase 4 gene, the muscarinic cholinergic receptor 2 gene, the interferon-related developmental regulator 1 gene, and protein-coupled receptor kinase 5 gene were correlated with the risk of TMD. ${ }^{(46)}$

\section{X linked disorders:}

More than $100 \mathrm{X}$ linked human hereditary disorders or traits have now been identified ${ }^{(47)}$. All the effects of sex chromosomes on periodontal disease have been associated with the $\mathrm{X}$ chromosome. Regarding many of the X-linked conditions reviewed, the association of gingivitis and/or periodontitis reported with the syndrome has been inconsistent and raises the question of whether the observed periodontal manifestations were truly a constant finding, arising as a result of the underlying genetic etiology of the condition. ${ }^{(48)}$

Evidence to association between X-linked genetic diseases and periodontal diseases are lacking and a relationship between these two entities cannot be adequately substantiated. To determine if there is truly a disease association between an X-linked 
syndrome and periodontitis, standardized, masked studies with sufficient power will be required.

\section{$\mathrm{X}$-linked diseases and their implication on tooth loss}

Disorders associated with the X-chromosome have been reported to affect periodontal health in various degrees. Severe irreversible forms of periodontitis can be linked to genetic factors. ${ }^{(49)}$

It is well established that periodontal health plays an important role in differences of tooth retention, edentulism, and rate of tooth loss among patients. That is to say that periodontal health will directly affect the rate by which teeth are extracted among those suffering from such diseases. ${ }^{(50)}$

The following diseases are among some of $\mathrm{X}$-linked diseases that affects periodontal health and bone loss patterns and therefore directly affects the rate of tooth loss.

Lowe syndrome (oculocerebrorenal syndrome), which is a X-linked recessive disorder due to mutation in OCRL1 gene in X-chromosome has a wide array of documented periodontal findings like periodontitis with severe bone loss, tooth mobility, and widened periodontal ligaments. ${ }^{(51-53)}$

Hypophosphatemic rickets is another genetic $\mathrm{X}$-linked dominant variant of rickets where administration of Vitamin D is ineffective. It is also known as X-linked hypophosphatemia (XLH). XLH is due to a mutation in the phosphate-regulating endopeptidase gene leading to function loss of this gene (X- linked PHEX), resulting in fibroblast growth factor 23 (FGF23) overactivity. Among the dental findings are advanced periodontal diseases with general alveolar loss, recurrent abscesses and sinus tract involving trauma free and/or carious teeth of both dentitions especially anterior teeth. Such teeth may require extraction, and sometimes surgical resection. ${ }^{(54-56)}$

Amelogenesis imperfecta is a group of inherited disorders affecting maturation and mineralization of enamel. The X-linked variant differs from other variants as it affects both dentitions. It is caused by defect in Amelogenin gene, this gene which is represented on both $\mathrm{X}$ and $\mathrm{Y}$ chromosomes. The AMELX; amelogenin on X-chromosome contributes to $90 \%$ of the body amelogenin. Among the dental findings in amelogenesis imperfecta (be it X-linked or autosomal) include gingivitis, periodontitis, and poor oral hygiene with high caries index. These finding are mostly secondary finding due to rough enamel surface and inability to maintain proper oral hygiene due to tooth sensitivity. ${ }^{(57,58)}$

It is to be concluded that some $\mathrm{X}$-linked diseases affects periodontal health and alveolar bone loss, thus greatly influencing antemortem tooth loos (AMTL). Not enough evidence exists to truly associate $\mathrm{X}$-linked disease and progressive tooth loss due to multiple biases in research and the fact that progressive tooth loss cannot always be connected to presence of a X-linked disease exclusively. ${ }^{(59)}$

Genetic disorders can negatively impact oral health, and indications for periodontal care may be the first sign of an undiagnosed genetic disease. Until recently, the relationship between genetic disorders and periodontal disease was unclear. As our understanding of the underlying mechanisms and systemic pathophysiology of numerous genetic disorders broadens, new research has uncovered a possible association between these types of disorders and periodontal disease.

\section{X-linked diseases and their implication on TMDs}

TMDs are significantly more prevalent in women than in men, and sexual hormones, especially estrogen, may contribute to female predominance. ${ }^{(60)}$ Since, TMJ disc is made up of collagen and elastin and female hormones metabolically affect its cartilage cells. Estrogen along with progesterone, increases cytokines synthesis and has a role in remodeling and degenerative function affecting bone. ${ }^{(61,62)}$ 


\section{Autosomal disorders:}

Marfan syndrome (MFS) is an autosomal dominant genetic disorder affects connective tissues and caused by mutations in the fibrillin- 1 gene. Since the periodontium is rich in connective tissue, oral manifestations of MFS are common. Systemically, MFS is associated with cardiovascular disease complications that increase morbidity and mortality for MFS-affected individuals.

According to Suzuki et al ${ }^{(63)}$ periodontal pathogens provoke a host immuno-inflammatory response characterized by the release of cytokines and matrix metalloproteinases.

Other MFS-associated oral manifestations include hypoplastic enamel spots, root deformity, abnormal pulp shape, pulpal inclusions, calculus, and gingival inflammation, which increase the risk for dental disorders. Additionally, Suzuki et al found that individuals with MFS and cardiovascular disease exhibited a higher incidence of periodontitis compared to healthy controls.

Another interesting finding is the effect of MFS on the PDL, which is structurally damaged due to a mutation of the fibrillin-1 gene. Studies conducted to clarify the function of elastic fibers in the PDLs of healthy patients as compared to PDL cells of individuals with MFS reported a mutation in the cbEGF domain, which is a critical alteration of the fibrillin-1 gene.3,4 As a result, mutations of the fibrillin-1 gene affect the normal development and function of the PDL fibers and make it more susceptible to periodontal breakdown. ${ }^{(64-66)}$

Ehlers-Danlos syndrome (EDS) is a heterogeneous connective tissue disorder characterized by variable degrees of skin hyperextensibility, fragility, scarring, minimal-to-moderate joint hypermobility (usually limited to the digits), and increased likelihood of bruising upon light trauma. The Type VIII form of EDS is a rare autosomal dominant disorder that exhibits periodontal manifestations. Rahman et al ${ }^{(67)}$ reported that EDS is a disorder of the metabolism of fibrillar collagen. Mao and Bristow ${ }^{(68)}$ demonstrated that gene mutations (COL5A1 or
COL5A2) play a role in the classic EDS presentation. Additional mutations (tenascin-X) have been reported, suggesting effects beyond that of collagen metabolism alone. ${ }^{(69)}$

Currently, there are no consistent molecular or biochemical markers that can detect EDS Type VIII. Unlike other types of EDS, severe early onset periodontitis is a primary oral feature of EDS Type VIII.5

Rahman et al ${ }^{(67)}$ examined the dental features, dermatological features and other clinical abnormalities consistent with the diagnosis of EDS in a large family consisting of five generations. The investigation showed demonstrable gingival recession and severe periodontal inflammation first identifiable in childhood, with rapid progression through adolescence and adulthood. Radiographs of selected family members indicated progressive loss of the hard and soft tissues of the periodontium, leading to edentulism. They identified a candidate gene on chromosome 12, but this was not consistent across the families, suggesting that EDS Type VIII is a genetically heterogeneous disorder.

Papillon-Lefèvre syndrome (PLS) is a rare autosomal recessive disorder that can manifest as periodontitis. Affected individuals exhibit a homozygous mutation within the gene that encodes lysosomal protease cathepsin C (CTSC), that expressed in epithelial and immune cells (mainly neutrophils and macrophages). The genetic mutations of CTSC gene expresses the two distinguishing clinical hallmarks of PLS. The first increase susceptibility to periodontitis, especially at a young age. Second, since CTSC is expressed on epithelial cells, mutations of the CTSC gene will lead to gross thickening of the palmoplantar hyperkeratosis. ${ }^{(70)}$

Neurofibromatosis is an autosomal dominant neurocutaneous syndrome "characterized by multiple cutaneous lesions and tumors of the central and peripheral nervous system." 10 Individuals with neurofibromatosis Type I (NF-1) exhibit oral manifestations in nearly $72 \%$ of cases. Javed et al reported that affected individuals exhibit 
unilateral non-tender enlargement of the gingiva, periodontitis, impacted and supernumerary teeth, morphological changes in teeth, and an Angle Class III molar relationship. Patients with NF-1 also tend to have poor and irregular oral hygiene, which can lead to gingival bleeding and excessive plaque. ${ }^{(71,72)}$

\section{Epigenetics and oral diseases}

Epigenetics in dental research is at the early stages and most of studies focus on medicine and biology. However, studies on epigenetics in dentistry deserve attention because epigenetic mechanisms play important roles in gene expression during tooth development and may affect oral diseases. DNA methylation, histone modification, and non-coding RNAs are epigenetic mechanisms control genetic alterations. The three mentioned mechanisms are influenced by genomic imprinting, early development, environmental factors (such as diet, smoking \& age), inflammation and cancer ${ }^{(73)}$

DNA methylation is crucial for proper regulation of the genome. According to recent studies in the field of dentistry, DNA methylation patterns can be altered by a persistent inflammation ${ }^{(74,75)}$. Changes of DNA methylation patterns and cytokine gene expression can be noticed in chronic periodontitis (76-78). In addition, healthy and inflamed dental pulp show different methylation patterns ${ }^{(79)}$.

Previous studies revealed the relationship between DNA methylation, periodontitis, and systemic diseases. The epigenetic regulation in RA and periodontitis were evaluated and compared. It has been found that periodontitis shares Rheumatoid arthritis (RA) the pathogenesis pathway ${ }^{(74,75,80)}$.

The possible association between chronic periodontitis and cancer on the molecular level interpret why periodontitis was associated with high ratios of cancer mortality ${ }^{81,82)}$.

Epigenetic changes in periodontitis and breast cancer have been evaluated by Loo et al. (2016). The results revealed that the promoters of Cadherin and $\mathrm{COX} 2$ were hypermethylated the most frequently in breast cancer, followed by periodontitis and the least frequently in controls ${ }^{\left({ }^{(8)}\right.}$

In another investigation assessing the methylation status of the extracellular matrix (ECM) organization-related genes, findings indicated that smoking might change the transcription and methylation status of ECM organization-related genes, which aggravated the periodontal disease ${ }^{(84)}$

Recent studies have reported that histone modifications may induce differentiation and mineralization in dental pulp stem cells. Histone acetylations and deacetylations play crucial roles in regulations of gene expression and promote pulp repair and regeneration ${ }^{(85-87)}$.

Non-coding RNAs are involved in oral diseases, as reported in dental studies, such as specific syndromes, oral cancer, and oral immunology. ${ }^{42,43}$ In addition, recent studies have demonstrated that miRNAs play essential roles in odontoblast differentiation. ${ }^{(88,89)}$

\section{Folate metabolism \& TMDs}

Myofascial pain and dysfunction are highly influenced by nutritional lack of folic acid, and these deficiencies are frequent in cases of mechanical stress of the TMJ. Folate metabolism participate in the synthesis of nucleic acid, and its role in regulating DNA and protein methylation has an impact on the formation of any growing tissue. Four polymorphic variants of three genes related to folate metabolism have been found to be associated with a higher risk of TMD. ${ }^{(90)}$ The first of these genes is the serine hydroxymethyl transferase 1 gene, encoding the homonymous enzyme that intervenes in the folate synthesis. A second gene is the methylenetetrahydrofolate dehydrogenase 1 , encoding another enzyme involved in folate synthesis. The polymorphism of the gene of another enzyme, the methionine synthase reductase, has been related to higher risk of TMD. The metabolic effect of all these variants is similar, causing the result of augmenting folate levels. ${ }^{(91)}$ 


\section{REFERENCES}

1. de Leeuw R, Klasser GD, editors. Orofacial pain: guidelines for assessment, diagnosis, and management. 5th ed. Chicago, IL: Quintessence; 2013. p. 127-86.

2. Landi N, Manfredini D, Tognini F, Romagnoli M, Bosco M. Quantification of the relative risk of multiple occlusal variables for muscle disorders of the stomatognathic system. J Prosthet Dent. 2004;92:190-5.

3. Michelotti A, Farella M, Gallo LM, Veltri A, Palla S, Martina R. Effect of occlusal interference on habitual activity of human masseter. J Dent Res. 2005;84:644-8.

4. Selaimen CM, Jeronymo JC, Brilhante DP, Lima EM, Grossi PK, Grossi ML. Occlusal risk factors for temporomandibular disorders. Angle Orthod. 2007;77:471-7.

5. Herken H, Erdal E, Mutlu N, et al. Possible association of temporomandibular joint pain and dysfunction with a polymorphism in the serotonin transporter gene. Am J Orthod Dento facial Orthop. 2001;120(3):308-313.

6. Mladenovic I, Supic G, Kozomara R, et al. Genetic polymorphisms of catechol-o-methyltransferase: association with temporomandibular disorders and postoperative pain. J Oral Facial Pain Headache. 2016; 30(4):302-310.

7. Suvinen TI, Reade PC, Kemppainen P, Kononen M, Dworkin SF. Review of aetiological concepts of temporomandibular pain disorders: towards a biopsychosocial model for integration of physical disorder factors with psychological and psychosocial illness impact factors. Eur J Pain. 2005;9(6):613-633.

8. Manfredini D, Landi N, Bandettini Di Poggio A, Dell'Osso L, Bosco M. A critical review on the importance of psychological factors in temporomandibular disorders. Minerva Stomatol. 2003;52(6):321-330.

9. Bertoli FMP, Bruzamolin CD, Kranz GOA, LossoEM BJA, Souza JF. Anxiety and malocclusion are associated with temporomandibular disorders in adolescents diagnosed by RDC/TMD. A cross-sectional study. J Oral Rehabil. 2018;45:747-755.

10. Slade GD, Sanders AE, Ohrbach R, et al. COMT Diplotype amplifies effect of stress on risk of temporomandibular pain. J Dent Res. 2015;94(9):1187-1195.

11. Kinane DF, Hart TC. Genes and gene polymorphisms associated with periodontal disease. Crit Rev Oral Biol Med 2003: 14: 430-449.
12. Hart TC, Kornman KS. Genetic factors in the pathogenesis of periodontitis. Periodontol 2000 1997: 14: 202-215.

13. Kamer AR, Craig RG, Dasanayake AP, Brys M, GlodzikSobanska L, de Leon MJ. Inflammation and Alzheimer's disease: possible role of periodontal diseases. Alzheimers Dement. 2008;4:242-250.

14. Sharpe PT. Homeobox genes and orofacial development. Connect Tissue Res 1995; 32:17-25.

15. Vastardis H, Karimbux n, Guthua SW, Seidman CE. A human MSX1 homeodomain missense mutation causes selective tooth agenesis. Nat Genet 1996; 13:417-21.

16. Peck S, Katja M. The palatally displaced canine as a dental anomaly of genetic origin. Angle Orthod. 1994; 64:249-56.

17. Cakan DG, Ulkur F, Taner T. The genetic basis of dental anomalies and its relation to orthodontics. Eur J Dent. 2013; 7(Suppl 1):143-145.

18. Otto F, Kanegane H, Mundlos S. Mutations in RUNX2 gene in patients with cleidocranial dysplasia. Hum Mutat. 2002; 19(3): 209-16.

19. Basaran G, Erkan M. One of the rarest syndromes in dentistry: gardner syndrome. Eur J Dent. 2008; 2(3):20812.

20. Gupta M, Jyoti B, Srivastava R, Pachauri A. Human genetic in oral medicine. A review. J Indian Acad Oral Med Radiol. 2014; 26:62-8.

21. Rhodin K, Divaris K, North KE, Barros SP, Moss K, Beck $\mathrm{JD}$, et al. Chronic periodontitis genome-wide association studies: Gene-centric and gene set enrichment analyses. Journal of Dental Research. 2014;93(9):882-890

22. Hong KW, Shin MS, Ahn YB, Lee HJ, Kim HD. Genomewide association study on chronic periodontitis in Korean population: Results from the Yangpyeong health cohort. Journal of Clinical Periodontology. 2015;42(8):703-710

23. Divaris K, Monda KL, North KE, et al. Exploring the genetic basis of chronic periodontitis: A genome-wide association study. Human Molecular Genetics. 2013; 22(11):2312-2324

24. Offenbacher S, Divaris K, Barros SP, Moss KL, Marchesan JT, Morelli T, et al. Genome-wide association study of biologically informed periodontal complex traits offers novel insights into the genetic basis of periodontal disease. Human Molecular Genetics. 2016;25(10):2113-2129 
25. Meloto CB, Serrano PO, Ribeiro-DaSilva MC, Rizzati-Barbosa CM. Genomics and the new perspectives for temporomandibular disorders. Arch Oral Biol. 2011;56:1181-91.

26. Liljestro“m MR, Aromaa M, Bell YL, Ja“msa“ T, Helenius $\mathrm{H}$, Virtanen R, et al. Familial occurrence of signs of temporomandibular disorders in headache children and their mothers. Acta Odontol Scand. 2007;65:134-40.

27. Huang B, Takahashi K, Sakata T, Kiso H, Sugal M, Fujimura $\mathrm{K}$, et al. Increased risk of temporomandibular joint closed-lock: a case-control study of ANKH polymorphisms. PLoS One. 2011;6:e25503.

28. Henry CH, Nikaein A, Wolford LM. Analysis of human leukocyte antigens in patients with internal derangement of the temporomandibular joint. J Oral Maxillofac Surg. 2002;60:778- 83 .

29. Learreta JA, Bono AE, Durst AC. HLA analysis in patients with degenerative diseases of the temporomandibular joint. J Craniomandib Pract. 2011;29:32-7.

30. Muroi Y, Kakudo K, Nakata K. Effects of compressive loading on human synovium-derived cells. J Dent Res. 2007;86(8):786- 91 .

31. Visse R, Nagase H. Matrix metalloproteinases and tissue inhibitors of metalloproteinases: structure, function, and biochemistry. Circ Res. 2003;92:827-39.

32. Nagase H, Visse R, Murphy G. Structure and function of matrix metalloproteinases and TIMPs. Cardiovasc Res. 2006;69(3):562-73.

33. Peng WJ, Yan JW, Wan YN, Wang BX, Tao JH, Yang GJ, et al. Matrix Metalloproteinases: a review of their structure and role in systemic sclerosis. J Clin Immunol. 2012;32(6):1409- 1414 .

34. Gottschalk M, Domschke K. Genetics of generalized anxiety disorder and related traits. Dialogues Clin Neurosci. 201.

35. Mladenovic I, Supic G, Kozomara R, et al. Genetic polymorphisms of catechol-o-methyltransferase: association with temporomandibular disorders and postoperative pain. J Oral Facial Pain Headache. 2016;30(4):302-310.

36. . Slade GD, Sanders AE, Ohrbach R, et al. COMT Diplotype amplifies effect of stress on risk of temporomandibular pain. J Dent Res. 2015;94(9):1187-1195.

37. Serrano PO. Polimorfismo Genético da Catecolamina -0- Metiltransferase (Val 158 Met) e Disfunção Temporo- mandibular em mulheres. Doctoral thesis, Universidade Estadual de Campinas, 2010; 119p.

38. Tchivileva IE, Lim PF, Smith SB, et al. Effect of catecholO-methyltransferase polymorphism on response to propranolol therapy in chronic musculoskeletal pain: a randomized, double-blind, placebo-controlled, crossover pilot study. Pharmacogenet Genomics. 2010;20(4):239-248.

39. Furquim BA. Potencial Influência de Variantes Genéticas nas Disfunções Temporomandibulares. Doctoral thesis, Universidade de São Paulo, Bauru, 2013; 128p.

40. Michelotti A, Liguori R, Toriello M, et al. CatecholOmethyltransferase (COMT) gene polymorphisms as risk factor in temporomandibular disorders patients from Southern Italy. Clin J Pain. 2014;30(2):129-133.

41. Smith SB, Reenilä I, Männistö PT, et al. Epistasis between polymorphisms in COMT, ESR1, and GCH1 influences COMT enzyme activity and pain. Pain. 2014;155(11):23902399.

42. Bonato LL, Quinelato V, Cordeiro PCF, et al. Polymorphisms in COMT, ADRB2 and HTR1A genes are associated with temporomandibular disorders in individuals with other arthralgias. Cranio. 2019. 2: 1-11.

43. Brancher JA, Spada PP, Meger MN, et al. The association of genetic polymorphisms in serotonin transporter and catechol-O-methyltransferase on temporomandibular disorders and anxiety in adolescentes. J Oral Rehabil. 2019; 46(7):597-604.

44. Li S, Jin Y, Wang H, Li Y. Role of apoptosis and bcl-2 gene in the temporomandibular joint development. Hua Xi Kou Qiang Yi Xue Za Zhi 1999;17:205-7.

45. Li S, Jin Y, Wang H. The role of bcl-2 and bax genes and programmed cell death in the temporomandibular joint development. Zhonghua Kou Qiang Yi Xue Za Zhi 2000;35:266-8.

46. Smith SB, Maixner DW, Greenspan JD, Dubner R, Fillingim RB, Ohrbach R, et al. Potential genetic risk factors for chronic TMD: genetic associations from the OPPERA case control study. J Pain. 2011;12:(11 Suppl):T92-101.

47. Germain D. Fabry disease: perspectives from 5 years of FOS. In: Mehta A, Beck M, Sunder-Plassmann G, editors. General aspects of X-linked diseases, Chapter 7. Oxford: Oxford PharmaGenesis, 2006: 63-68

48. HUA-HONG CHIEN \& THOMAS C. HARTDo X-linked diseases affect periodontal health? Sex chromosomes and Mendelian 
49. Chien HH, Hart TC. Do X-linked diseases affect periodontal health? Periodontol 2000. 2013 Feb;61(1):266-78.

50. Russell SL, Gordon S, Lukacs JR, Kaste LM. Sex/Gender differences in tooth loss and edentulism: historical perspectives, biological factors, and sociologic reasons. Dent Clin North Am. 2013 Apr;57(2):317-37.

51. Harrison M, Odell EW, Sheehy EC. Dental findings in Lowe syndrome. Pediatr Dent 1999: 21: 425-428.

52. Rodrigues Santos MT, Watanabe MM, Manzano FS, Lopes $\mathrm{CH}$, Masiero D. Oculocerebrorenal Lowe syndrome: a literature review and two case reports. Spec Care Dentist 2007: 27: 108-111.

53. Tsai SJ, ODonnell D. Dental findings in an adult with Lowes syndrome. Spec Care Dentist 1997: 17: 207-210.

54. Sabandal, M. M. I., Robotta, P., Bürklein, S. \& Schäfer, E. Review of the dental implications of X-linked hypophosphataemic rickets (XLHR). Clin. Oral. Investig. 19, 759-768.(2015) .

55. Vital, S. O. et al. Tooth dentin defects reflect genetic disorders affecting bone mineralization. Bone 50, 989-997 .(2012)

56. Connor, J. et al. Conventional therapy in adults with Xlinked hypophosphatemia: effects on enthesopathy and dental disease. J. Clin. Endocrinol. Metab. 100, 36253632.(2015)

57. Witkop CJ Jr. Amelogenesis imperfecta, dentinogenesis imperfecta and dentin dysplasia revisited: problems in classification. J Oral Pathol 1988: 17: 547-553.

58. Poulsen S, Gjorup H, Haubek D, Haukali G, Hintze H, Lovschall H, Errboe M. Amelogenesis imperfecta - a systematic literature review of associated dental and orofacial abnormalities and their impact on patients. Acta Odontol Scand 2008: 66: 193-199.

59. Chien HH, Hart TC. Do X-linked diseases affect periodontal health? Periodontol 2000. 2013 Feb;61(1):266-78.

60. Wang J, Chao Y, Wan Q, Zhu Z. The possible role of estrogen in the incidence of temporomandibular disorders. Med Hypotheses. 2008;71:564-7.

61. Warren MP, Fried JL. Temporomandibular disorders and hormones in women. Cells Tissues Organs. 2001;169(3):187-92. 17.

62. Abubaker AO, Hebda PC, Gunsolley JN. Effects of sex hormones on protein and collagen content of the temporomandibular joint disc of the rat. J Oral Maxillofac Surg. 1996;54(6):721-7.
63. Suzuki J, Aoyama N, Izumi Y, Isobe M, Komuro I, Hirata Y. Effect of periodontitis on cardiovascular manifestations in Marfan syndrome. Critical common role of TGF- $\beta$. Int Heart J. 2015;56:121-124.

64. Ohshima M, Yamaguchi Y, Matsumoto N, et al. TGF- $\beta$ signaling in gingival fibroblast-epithelial interaction. J Dent Res. 2010;89:1315-1321.

65. Shiga M, Saito M, Hattori M, et al. Characteristic phenotype of immortalized periodontal cells isolated from a Marfan syndrome type I patient. Cell Tissue Res. 2008;33:461-472.

66. Suda N, Shiga M, Ganburged G, Moriyama K. Marfan syndrome and its disorder in periodontal tissues. J Exp Zool B Mol Dev Evol. 2009;312B:503-509.

67. Rahman N, Dunstan M, Teare MD, et al. Ehlers-Danlos syndrome with severe early-onset periodontal disease (EDS-VIII) is a distinct, heterogeneous disorder with one predisposition gene at chromosome 12p13. Am J Hum Genet. 2003; 73:198-204.

68. Mao JR, Bristow J. The Ehlers-Danlos syndrome: on beyond collagens. J Clin Invest. 2001; 107:1063-1069.

69. Schalkwijk J, Zweers MC, Steijlen PM, et al. A recessive form of the Ehlers-Danlos syndrome caused by tenascin-X deficiency. N Engl J Med. 2001; 345:1167-1175.

70. Ragunatha S, Ramesh M, Anupama P, Kapoor M, Bhat M. Papillon-Lefèvre syndrome with homozygous nonsense mutation of cathepsin $\mathrm{C}$ gene presenting with late-onset periodontitis. Pediatr Dermatol. 2015; 32:292-294.

71. Javed F, Ramalingam S, Ahmed HB, et al. Oral manifestations in patients with neurofibromatosis type-1: a comprehensive literature review. Crit Rev Oncol Hematol. 2014; 9:123-129.

72. Ghalayani P, Saberi Z, Sardari F. Neurofibromatosis type I (von Recklinghausen's disease): A family case report and literature review. Dent Res J (Isfahan). 2012; 9:483-488.

73. Ji-Yun Seo1, Yoon-Jung Park2, Young-Ah Yi3, Ji-Yun Hwang4, In-Bog Lee1, Byeong-Hoon Cho1, Ho-Hyun Son1, Deog-Gyu Seo1 .Epigenetics: general characteristics and implications for oral health. Restorative Dentistry \& Endodontics 2015; 40(1): 14-22.

74. Gomez RS, Dutra WO, Moreira PR. Epigenetics and periodontal disease: future perspectives. Inflamm Res. 2009; 58:625-629. 
75. Lindroth AM, Park YJ. Epigenetic biomarkers: a step forward for understanding periodontitis. J Periodontal Implant Sci. 2013; 43:111-120.

76. Zhang S, Crivello A, Offenbacher S, Moretti A, Paquette DW, Barros SP. Interferon-gamma promoter hypomethylation and increased expression in chronic periodontitis. J Clin Periodontol. 2010; 37:953-961.

77. Zhang S, Barros SP, Moretti AJ, Yu N, Zhou J, Preisser JS, Niculescu MD, Offenbacher S. Epigenetic regulation of TNFA expression in periodontal disease. J Periodontol. 2013; 84:1606-1616.

78. Zhang S, Barros SP, Niculescu MD, Moretti AJ, Preisser JS, Offenbacher S. Alteration of PTGS2 promoter methylation in chronic periodontitis. J Dent Res. 2010; 89:133137.

79. Cardoso FP, Viana MB, Sobrinho AP, Diniz MG, Brito JA, Gomes CC, Moreira PR, Gomez RS. Methylation pattern of the IFN-gamma gene in human dental pulp. J Endod. 2010; 36:642-646.

80. Soory, M. Association of periodontitis with rheumatoid arthritis and atherosclerosis: Novel paradigms in etiopathogeneses and management? Open Access Rheumatol. Res. Rev. 2010, 2, 1.

81. Romandini, M.; Baima, G.; Antonoglou, G.; Bueno, J.; Figuero, E.; Sanz, M. Periodontitis, Edentulism, and Risk of Mortality: A Systematic Review with Meta-analyses. J. Dent. Res. 2021, 100, 37-49.

82. Söder, B.; Yakob, M.; Meurman, J.H.; Andersson, L.C.; Klinge, B.; Söder, P.-Ö. Periodontal disease may associate with breast cancer. Breast Cancer Res. Treat. 2011, 127, 497-502.

83. Paino F, La Noce M, Tirino V, Naddeo P, Desiderio V, Pirozzi G, De Rosa A, Laino L, Altucci L, Papaccio G. Histone deacetylase inhibition with valproic acid downregulates osteocalcin gene expression in human dental pulp stem cells and osteoblasts: evidence for HDAC2 involvement. Stem Cells. 2014; 32:279-289.

84. Wang T, Liu H, Ning Y, Xu Q. The histone acetyltransferase $\mathrm{p} 300$ regulates the expression of pluripotency factors and odontogenic differentiation of human dental pulp cells. PLoS One. 2014; 9:e102117.

85. Duncan HF, Smith AJ, Fleming GJ, Cooper PR. Histone deacetylase inhibitors induced differentiation and accelerated mineralization of pulp-derived cells. J Endod. 2012; 38:339-345.

86. Duncan HF, Smith AJ, Fleming GJ, Cooper PR. Histone deacetylase inhibitors epigenetically promote reparative events in primary dental pulp cells. Exp Cell Res. 2013; 319:1534-1543.

87. Duncan HF, Smith AJ, Fleming GJ, Cooper PR. HDACi: cellular effects, opportunities for restorative dentistry. J Dent Res. 2011; 90:1377-1388.

88. Sun Q, Liu H, Chen Z. The fine-tuning role of microRNARNA interaction in odontoblast differentiation and disease. Oral Dis. 2014; 03. 22. doi: 10.1111/odi.12237. [Epub ahead of print].

89. Perez P, Jang SI, Alevizos I. Emerging landscape of noncoding RNAs in oral health and disease. Oral Dis. 2014; 20:226-235.

90. Aneiros-Guerrero A, Lendinez AM, Palomares AR, PerezNevot B, Aguado L, Mayor-Olea A, et al. Genetic polymorphisms in folate pathway enzymes, DRD4 and GSTM1 are related to temporomandibular disorder. BMC Med Genet. 2011;12:75-83.

91. Melis M, Giosia M D. The role of genetic factors in the etiology of temporomandibular disorders: a review. The Journal of Craniomandibular \& Sleep Practice 2014 VOL. 0002 NO. 00027. 